\title{
Financial constrains in the health sector: Romanian place in European perspective with a focus on rheumatic disease
}

\author{
Florian Berghea
}

"Carol Davila" University of Medicine and Pharmacy, Bucharest, Romania

\begin{abstract}
Health represents both a personal and social asset different valued by individuals and populations. Personal education, previous experience, sex, income or housing variables contribute to a higher or lower prioritization of health care. Different actors interfere their forces and interests in this area: industry is interested in profit, administration is interested in a healthier and productive population, politicians are interested in accomplishing their agenda, patients want to pay less and receive more benefits etc. As European Union is still very inhomogeneous in terms of wealth, education or previous experience with health sector is clear that a large pool of differences could observed among EU28 countries.

Objectives. In this paper we are analyzing EU official statistical data to understand these differences and find practical conclusions for what Romanian health system intend to be.

Methods. Analyses of EU statistics public available in Eurostat directory.

Results. We analyzed how developed and what are the outcomes of EU health sector with a focus on Romania and rheumatology field.

Discussions and conclusions. There is no a clear link between different components of health sector and the way these are financed and the outcome.
\end{abstract}

Keywords: health system, health economy, health services, European Union

The financial dimensions of health sector are always a matter to debate. Several particularities of this area can explain this but above all is the special nature of health sector outcome: the health itself. Entirely not tangible and usually defined as opposite to illness, the health is somehow perceived by every person as a human right. But, in the human rights package, the health (mentioned in article 25 of Universal Declaration of Human Rights (1)) has a singular nature, too: it is given and not produced and preserved from the interaction with other individuals or with the society (as compared with dignity, freedom of opinion or right to education that appear only in conjunction with the society) (1). On the other hand, one-person health might exist but cannot be preserved (in the way we are seeing the health now) without the interaction with other individuals and in a larger view with the society. No matter how the health status of a newborn is, no matter how deep will be going to be his medical knowledge after years, no human being can preserve undefinedly his health status without any interaction with other individuals. Medical devices (from the needle to laser beam) and chemical products (from alcohol disinfectants to biological therapy) are delivered by others. At a cost.

The players of health sector that interact can be divided in suppliers (as pharma companies, health service suppliers), managers (as health insurance bodies, ministers of health) and receivers (in general terms - patients). In simple words we have receivers that demand health services that are delivered by certain suppliers in a way decided by managers. However, the relation is much more complicated part because each player can act in a dual way (e.g. doctors are both suppliers - they offer health services- but also managers - they select what product is to be delivered to their patients) and part because each player can (and usually do) influence other players with the final aim of an increased profit. In the area 
of rheumatic diseases, we could imagine how pharma companies with a strong portfolio will be interested to communicate with doctors accommodated with their portfolio (and will promote this accommodation); in the same time same pharma companies will be interested to have partnerships both with managers that consider rheumatology as being top priority and patients that consider pharma portfolio as the solution to their demand. Is simple to understand how pharma industry will try to promote its interests in relation with other players. On the other hand, the managers (let's focus on health insurance body) usually try to maximize both the health profit (i.e. to obtain better conditions not only for rheumatic but for cardiac or diabetic patients, too) and the public image profit (i.e. to maximize the number of health insurance payers that are satisfied with what they get from the health system managed by this insurance body). In this regard, the health insurance body collect data about what is important for the individual tax payers and conduct education campaigns to promote what is considered important for the whole society. In the same time an insurance house will promote medical and administrative-medical decisions that help it to reach its goals and here we are in touch with health policy. And so on.

Finally, there are costs: every player is shaping its attitude based on a cost evaluation. Despite the general perception that cost, and price are the same we should emphasize that in fact they aren't. In fact the general public is mostly focused on the financial cost that represents actual expenditure on goods and services purchased (2) but we have to work with economic costs that includes the additional estimat- ed value of goods or services for which there are no financial transactions or when the price of the good does not reflect the cost of using it productively elsewhere (2). In a more simplified way the cost is the measure of a sacrifice consumed to produce the respective item, a sacrifice that can not be always measured in monetary terms: an outpatient consultation will cost 10 sqm of a medical premises used for 15 minutes, 15 minutes from the doctor and nurse time, $1 \mathrm{sqm}$ from the waiting room occupied by this patient of 30 minutes, a certain part of the lab and drug costs associated to this consultation and so on. Is the hospital willing to sacrifice $10 \mathrm{sqm}$ for 15 mins for this patient or is it able to do it in a more profitable way? Is the doctor willing to sacrifice 15 minutes for this patient or has he a better alternative? And how do you compare the alternative when it is represented by leisure time (with no financial benefit for this doctor)?

Having these in mind we decided to analyses European data available in the Eurostat directory (3) to understand how the rheumatology (and especially Romanian rheumatology) is positioned in the general picture of European health sector. We must take into consideration that EU countries have in common a general tendency to ageing (decreased fertility, decreased mortality and increased life expectancy), a group of shared cultural values or some similar economical directions (e.g. a certain limit of public deficit).

The total population of EU28 in 2017 was about 511,5 million. The proportion in that different countries contribute to this population is presented in Fig.1. It can be observed that once the UK will leave

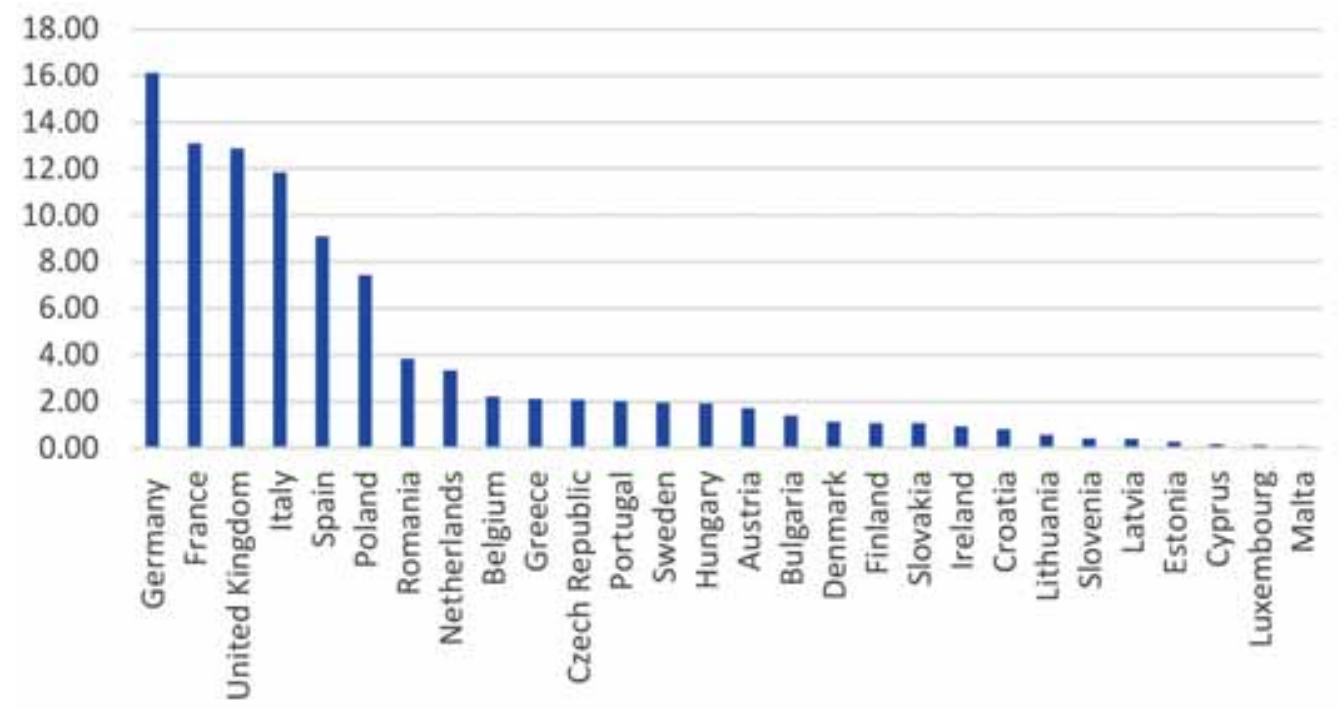

FIGURE 1. EU Population (percentage) 
EU, Romania will become the $6^{\text {th }}$ largest EU country (based on population).

The median age of population in EU28 2017 was 42.8 years and it is expected to increase once the UK (with a lower median age) will leave this group. Romania is situated below this median with a median of 41.8 years. A particular interesting indicator is self-perceived health. It is measure the subjective perception of each individ of his or her level of health. It is interesting to see how this indicator varies among the countries apparently not related to the GDP or median age (Fig. 2). In this case Romanians seem to consider them at least as healthy as austrians and far better than germans. With the exception of ireland, males consider themselves healthier than females in all EU countries. In Romania this difference is the highest: $10.5 \%$ more males consider themselves as being in a godd or very good state of health compared with females. In addition, there is a very small percentage of Romanians that declared themselves as having a chronic illness (in the last 12 months ended with the momment of the interview): $19.2 \%$ ( $2 \mathrm{nd}$ best place after Italy), that is much better than EU28 data (32.8\%) and far more better than in Finland (46.9\%). However, these data come in contradiction with declared medical unmet needs that place Romania in one of the worst places: $5.3 \%$ of Romanians have unmet medical needs because these services are too expensive (the 3rd worst place, EU28 level is $1.7 \%$ ), $0.6 \%$ of Romanians have unmet medical needs because these services are too far (3rd worst place, EU28 level is 0.1\%). But only $0.1 \%$ of Romanians have unmet medical needs be- cause they do not know a good doctor that is quite low $(0.1 \%$ in EU28) that is translated in a high degree of trust Romanians have in their doctors.

A different view is offered by "Absence from work due personal health problems". This indicator (computed for different levels of education of responders) has the best value in Romania (between 3.6 and $3.9 \%$ of Romanians declared such absence in the last 12 months) that is below EU28 (29.8 to $36.8 \%$ ) and very far from the worst place (Germany: 58 to $62.8 \%$ ). Data are available for 2014 only. Several factors could contribute to this situation as the volatility of labour market, local regulations that protect more or less the persons that have absence from work, the easines to get paid sik-leave days etc.

Regarding the health care expenditure, the situation in Romania is, unfortunately, far from the average level in EU28. Data are presented both in monetary units (EURO) and in adjusted monetary units PPS (that adjust EURO to local purchasing power). At the level of 2015 Romania spent 7.925 (Million, EURO) placing this jurisdiction on the 19th place in EU. When translating this in GDP related data, Romania spent $5.7 \%$ of its GDP for health (2nd worst place in UE) that is equivalent with 399.96 EURO per year per inhabitant (worst place in EU, the 2nd worst was Bulgaria with 517.54 EURO, see Fig. 3). Using PPT as adjusted monetary unit Romania was in the same place with app 865 PPTs spent per inhabitant in 2015.

The way this sum is spent among different functions shows that Romania and Bulgaria spent for pharmaceuticals the largest percentage when com-

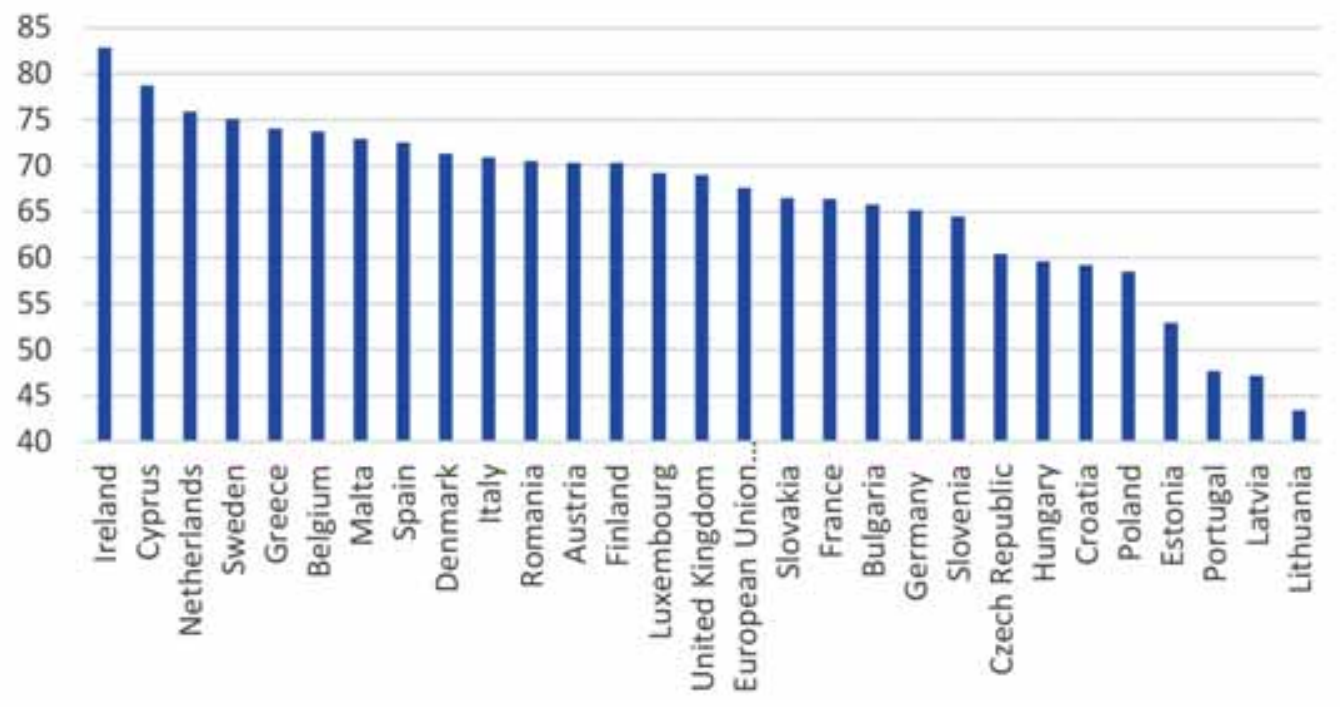

FIGURE 2. Self-perceived health (2016 data). 


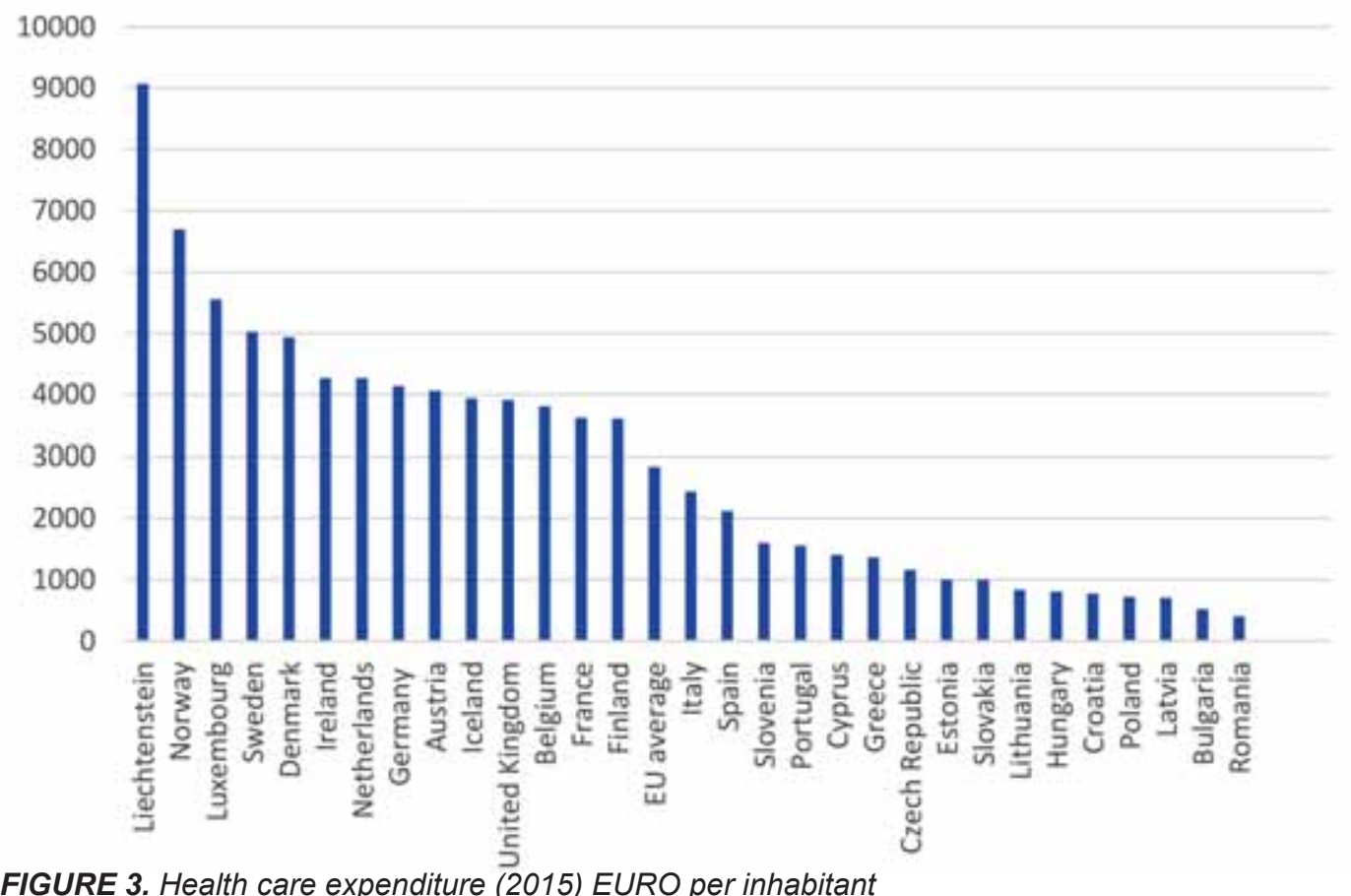

FIGURE 3. Health care expenditure (2015) EURO per inhabitant

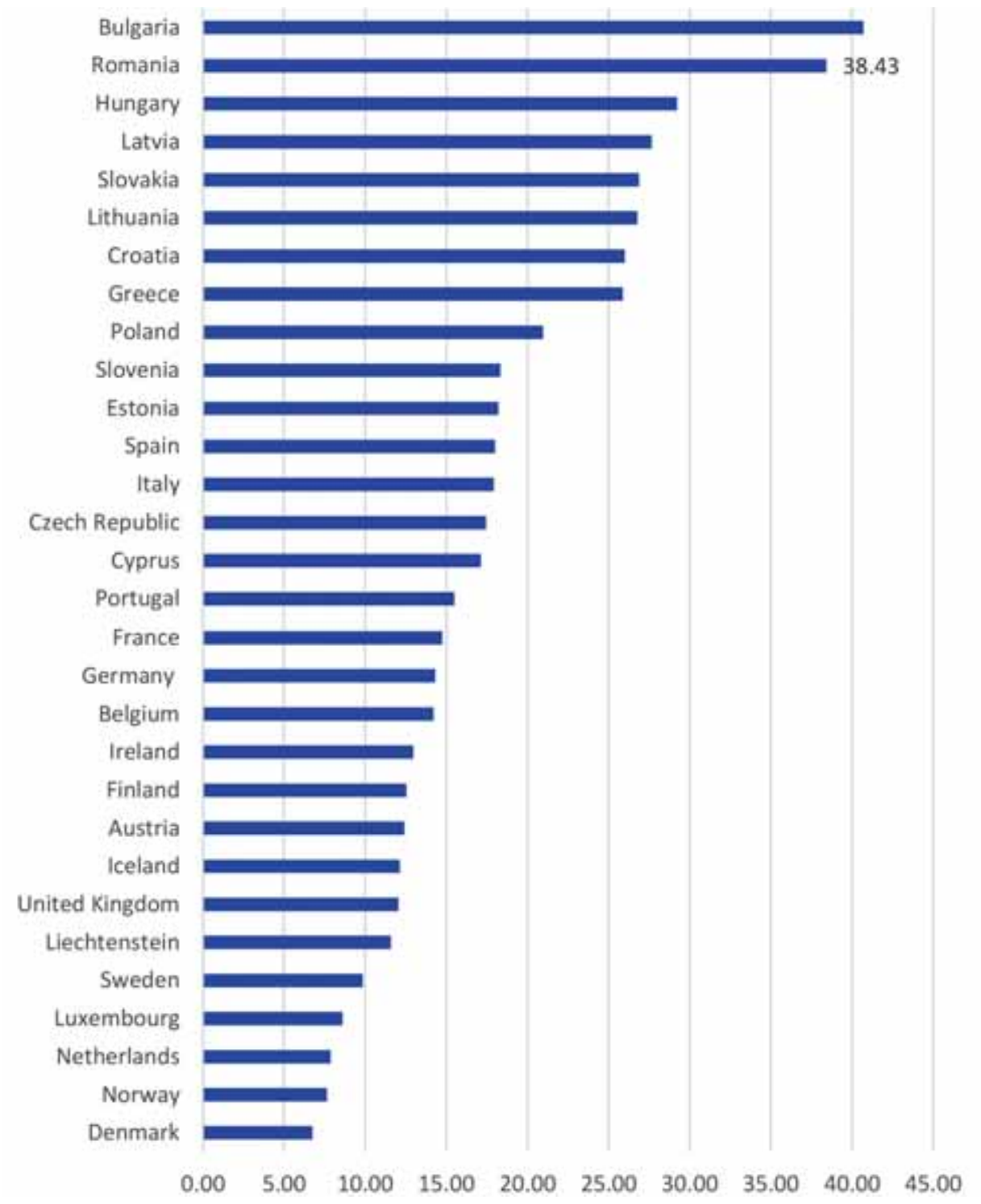

FIGURE 4. Proportion of pharmaceuticals in total health expenditure (2015) 
TABLE 1. Total hospital discharges in 2015.

\begin{tabular}{|c|c|c|c|c|c|c|c|c|c|c|c|}
\hline & $\begin{array}{c}\text { Populations } \\
2015\end{array}$ & Total MSK & $\mathrm{CO}$ & GO & SCD & SPA & $\begin{array}{l}\text { Total } \\
\text { MSK }\end{array}$ & $\mathrm{CO} / 1000$ & GO/1000 & $\mathrm{SCD} / 1000$ & SPA $/ 1000$ \\
\hline Bulgaria & $7,202,198$ & 114438 & 5404 & 4592 & 4962 & 9408 & 15.89 & 0.75 & 0.64 & 0.69 & 1.31 \\
\hline Czech Republic & $10,538,275$ & 171954 & 18102 & 21781 & 1733 & 6304 & 16.32 & 1.72 & 2.07 & 0.16 & 0.60 \\
\hline Denmark & $5,659,715$ & 45727 & 8653 & 8178 & 1563 & 6723 & 8.08 & 1.53 & 1.44 & 0.28 & 1.19 \\
\hline Estonia & $1,314,870$ & 14347 & $:$ & $:$ & 884 & $:$ & 10.91 & & & 0.67 & \\
\hline Ireland & $4,677,627$ & 27298 & 3751 & 2746 & 706 & 1142 & 5.84 & 0.80 & 0.59 & 0.15 & 0.24 \\
\hline Spain & $46,449,565$ & 344854 & $:$ & $:$ & 5415 & 17559 & 7.42 & & & 0.12 & 0.38 \\
\hline France & $66,456,279$ & 783088 & 103611 & 105447 & 14566 & 66213 & 11.78 & 1.56 & 1.59 & 0.22 & 1.00 \\
\hline Croatia & $4,225,316$ & 42843 & 4146 & 3849 & 1023 & 2861 & 10.14 & 0.98 & 0.91 & 0.24 & 0.68 \\
\hline Cyprus & 847,008 & 1487 & 132 & 344 & 62 & 66 & 1.76 & 0.16 & 0.41 & 0.07 & 0.08 \\
\hline Latvia & $1,986,096$ & 16493 & 2259 & 1867 & 305 & 6405 & 8.30 & 1.14 & 0.94 & 0.15 & 3.22 \\
\hline Lithuania & $2,921,262$ & 51209 & 4035 & 3942 & 873 & 4274 & 17.53 & 1.38 & 1.35 & 0.30 & 1.46 \\
\hline Luxembourg & 562,958 & 8622 & 839 & 1375 & 83 & 947 & 15.32 & 1.49 & 2.44 & 0.15 & 1.68 \\
\hline Hungary & $9,855,571$ & 193645 & 20565 & 20730 & 5520 & 29985 & 19.65 & 2.09 & 2.10 & 0.56 & 3.04 \\
\hline Malta & 439,691 & 2308 & 183 & 721 & 37 & 57 & 5.25 & 0.42 & 1.64 & 0.08 & 0.13 \\
\hline Austria & $8,584,926$ & 262567 & 30658 & 37500 & 4209 & 19335 & 30.58 & 3.57 & 4.37 & 0.49 & 2.25 \\
\hline Poland & $38,005,614$ & 314022 & 30472 & 27582 & 17121 & 28941 & 8.26 & 0.80 & 0.73 & 0.45 & 0.76 \\
\hline Portugal & $10,374,822$ & 38269 & $:$ & $:$ & 1003 & 2817 & 3.69 & & & 0.10 & 0.27 \\
\hline Romania & $19,870,647$ & 308397 & 16837 & 25589 & 9223 & 73010 & 15.52 & 0.85 & 1.29 & 0.46 & 3.67 \\
\hline Slovakia & $5,421,349$ & 75727 & 8185 & 8945 & 1367 & 2891 & 13.97 & 1.51 & 1.65 & 0.25 & 0.53 \\
\hline Finland & $5,471,753$ & 64688 & 10322 & 12745 & 1488 & 8948 & 11.82 & 1.89 & 2.33 & 0.27 & 1.64 \\
\hline Sweden & $9,747,355$ & 83540 & 14706 & 13417 & 3457 & 11796 & 8.57 & 1.51 & 1.38 & 0.35 & 1.21 \\
\hline United Kingdom & $64,875,165$ & 510729 & 80116 & 101603 & 6500 & 30290 & 7.87 & 1.23 & 1.57 & 0.10 & 0.47 \\
\hline Iceland & 329,100 & 1580 & 304 & 349 & 57 & 268 & 4.80 & 0.92 & 1.06 & 0.17 & 0.81 \\
\hline Liechtenstein & 37,366 & 462 & 10 & 58 & 5 & 12 & 12.36 & 0.27 & 1.55 & 0.13 & 0.32 \\
\hline Norway & $5,166,493$ & 54215 & 7894 & 6680 & 3098 & 5647 & 10.49 & 1.53 & 1.29 & 0.60 & 1.09 \\
\hline Switzerland & $8,237,666$ & 185188 & 22678 & 26065 & 1857 & 17599 & 22.48 & 2.75 & 3.16 & 0.23 & 2.14 \\
\hline Serbia & $7,114,393$ & 62204 & 5384 & 5580 & 2940 & 6657 & 8.74 & 0.76 & 0.78 & 0.41 & 0.94 \\
\hline Turkey & $77,695,904$ & 571187 & 14488 & 100467 & 6247 & 28064 & 7.35 & 0.19 & 1.29 & 0.08 & 0.36 \\
\hline
\end{tabular}

MSK - musculoskeletal, CO - coxarthrosis, GO - gonarthrosis, SCD - systemic connective diseases, SPA - spondyloarthritis

pared with all other EU countries (38.4\% and $40.7 \%$ respectively, see Fig. 4). This situation should be properly discussed - as long as the total funds spent in health sector remain so low in these countries their systems present a problematic disbalance between how different needs are fulfilled. It is clear that an economical prioritization is highly needed in such disbalanced situations.

With respect to rheumatic diseases and the way rheumatic patients are treated around the EU same source offers interesting data. Unfortunately, the density of rheumatologists is not available. However, it seems that Romania has the 3rd largest number in UE of doctors that are specialists in Occupational Medicine :2.909. Analyzing medical facilities, Romania offered in 2015 one hospital bed for about 194 inhabitants that placed our country in the last quarter of EU (Belgium, Austria, Bulgaria, Lithuania and Germany were offering even more beds per inhabitant). For rehabilitation hospitals Romania had a generous offer in the same year: app 1600 inhabitants for one rehabilitation bed compared with EU28 average of about 9000 inhabitants for the same bed.

One last information regarding rheumatic diseases available is related to total number of hospital discharges divided by diagnostic. Relevant data are pre- 
sented in table 1 . The proportions are very wide: from 1.76 discharges with Musculoskeletal disease per 1000 inhabitants in Cyprus to 30.58 discharges in Austria. Romania is situated somehow in the middle (with about 15.52/ 1000 inhabitants). Same discrepancies could be observed for coxarthrosis and gonarthrosis: in these cases Romania had 3 to 4 times less discharges than Germany (but almost the same rate of discharges with systemic connective diseases or spondyloarthritis).

After a careful evaluation and analysis of EUOROSTAT data several conclusions could be emphasized. First is that EU countries are far from being homogenous in terms of how much they afford to spend for health and how do they spend their budgets. It is obvious that less wealthy jurisdictions will spend less in monetary terms but in many cases the percent of GDP allocated to health is not related to the total level of GDP (or adjusted GDP per capita). Second striking conclusion is related to how the Europeans perceive their health and how their countries reflect this in health budget: a very poor relation exists here (i.e. Romania and Bulgaria have a high proportion of inhabitants that perceive themselves as being in a good and very good condition but are, in the same time, leaders of proportion of health budget spent for pharmaceuticals and among the leaders in the area of occupational medicine ("medicina muncii" in Romanian). Last but mot least are conclusions that come from Rheumatology area: it seems that wealthier jurisdictions do a larger number of hospital admissions for degenerative rheumatic disorders (as coxarthrosis and gonarthrosis) than jurisdictions with smaller budgets. On the other side the systemic connective diseases seem to be much more homogenous managed around the EU in terms of hospital admissions.

Health system is a difficult problem in every jurisdiction for simple fact that no economy can afford to pay for all health needs of the entire population. All jurisdictions must deal with different sort of penuries: personnel, technique, premises, pharmaceuticals. It is very seductive to believe the way each country allocates and spends the health resources represents the best option for that population and that year. It is seductive but is it true?

\section{REFERENCES}

1. Universal Declaration of Human Rights [Internet]. 2015 [cited 2018 Apr 30]. Available from: http://www.un.org/en/universal-declarationhuman-rights/index.html

2. Walker D. Cost and cost-effectiveness guidelines: which ones to use? Health Policy Plan. 2001 Mar;16(1):113-21.

3. Home - Eurostat [Internet]. [cited 2018 May 3]. Available from: http://ec.europa.eu/eurostat/web/main/home 